\title{
ANALISIS EFEKTIVITAS BIAYA PADA PASIEN ANAK DEMAM TIFOID DI RUMAH SAKIT BHAYANGKARA MANADO
}

\author{
Agatha Agnes S ${ }^{1)}$, Gayatri Citraningtyas ${ }^{1)}$, Sri Sudewi ${ }^{1)}$ \\ ${ }^{1)}$ Program Studi Farmasi FMIPA UNSRAT Manado, 95115
}

\begin{abstract}
Typhoid fever is an endemic disease which it incidence rate is still high in Indonesian. Administering antibiotic therapy can do treatment of typhoid fever. This study was conducted since there are several pediatric patients diagnosed with typhoid fever but have different antibiotic therapies, namely cefotaxime and ceftriaxone therapy, so it is necessary to do calculations to determine the comparison and determine which treatment is more efficient in cost and effectiveness. The method used in this study is CEA (CostEffectiveness Analysis) with the design of retrieving medical record data of children with typhoid fever in Bhayangkara Manado Hospital retrospectively from January to December 2018. The samples obtained were 28 pediatric patients, cinsisting of 12 patients using cefotaxime therapy and 16 patients using ceftriaxone therapy. The result of ACER (An Avarage Cost Effective Ratio) obtained by ceftriaxone were Rp. 526.609,-/day and cefotaxime Rp. 484.789,-/day. In this study, if patients under cefotaxime therapy want to swich treatment to ceftriaxone therapy, ICER calculation (Incremental Cost-Effectiveness Ratio) is carried out the result are $R p .340 .528,-$.
\end{abstract}

Keyword: Typhoid fever, Antibiotics, CEA (Cost-Effectiveness Analysis)

\begin{abstract}
ABSTRAK
Demam tifoid merupakan penyakit endemik yang angka kejadiannya masih tinggi di Indonesia. Pengobatan demam tifoid dapat diobati dengan cara pemberian terapi antibiotik. Penelitian ini dilakukan karena ada beberapa pasien anak yang di diagnosa demam tifoid tetapi memiliki terapi antibiotik yang berbeda, yaitu terapi sefotaksim dan seftriakson sehingga perlu dilakukan perhitungan untuk mengetahui perbandingan dan menentukan pemilihan pengobatan mana yang lebih efisien dalam biaya maupun efektivitas. Metode yang digunakan dalam penelitian ini adalah CEA (Cost-Effectiveness Analysis) dengan rancangan pengambilan data rekam medik pasien anak demam tifoid di RS. Bhayangkara Manado secara retrospektif pada periode Januari - Desember 2018. Sampel yang didapat sebanyak 28 pasien anak, yang terdiri dari 12 pasien pengguna terapi sefotaksim dan 16 pasien pengguna terapi seftriakson. Hasil ACER (An Avarage Cost Effective Ratio) yang diperoleh sefotaksim Rp.526.609,-/hari dan seftriakson Rp.484.789,/hari. Pada penelitian ini jika pasien terapi sefotaksim ingin berpindah pengobatan ke terapi seftriakson maka dilakukan perhitungan ICER (Incremental Cost-Effectiveness Ratio) dan didapat hasil Rp.340.582,-, sehingga jika ingin berpindah pengobatan maka perlu penambahan biaya sesuai nilaI ICER.
\end{abstract}

Kata Kunci : Demam Tifoid, Antibiotik, CEA (Cost-Effectiveness Analysis). 


\section{PENDAHULUAN}

Penyakit menular masih merupakan salah satu masalah kesehatan utama di negara berkembang. Salah satu penyakit menular tersebut adalah demam tifoid. Demam tifoid merupakan penyakit menular yang disebabkan oleh Salmonella typhi yang menginfeksi saluran pencernaan sehingga mengakibatkan peradangan pada bagian usus halus dan lumen usus (Etikasari dkk, 2012).

Angka Kejadian demam tifoid diperkirakan ada sekitar 17 juta kasus demam tifoid di dunia dan 600.000 diantaranya mengalami kematian. Sebanyak $91 \%$ kasus demam tifoid menyerang penduduk Indonesia yang berusia 6-11 tahun (WHO, 2014). Menurut Profil Kesehatan Indonesia (2014) demam tifoid menempati urutan ke-3 dari 10 penyakit terbanyak pasien rawat inap di Rumah Sakit yaitu sebanyak 41.081 kasus, yang meninggal 274 orang.

Terapi antibiotik merupakan pengobatan yang paling banyak digunakan, terkait dengan banyaknya kejadian infeksi bakteri yang diderita oleh banyak orang (Juwono, 2005). Antibiotik segera diberikan bila diagnosis telah dibuat. Antibiotik merupakan satu-satunya terapi yang efektif untuk demam tifoid (Hadinegoro, 2011). Menurut survei yang dilakukan di RS. Bhayangkara Manado, pasien anak penderita demam tifoid diberikan terapi antibiotik sefotaksim dan seftriakson. Pengobatan pada beberapa pasien dengan diagnosa yang sama, tetapi memiliki terapi antibiotik yang berbeda menjadi masalah dalam pemilihan alternatif pengobatan yang efisien dalam efektivitas maupun biaya.

Biaya dari terapi obat merupakan konsep dari biaya yang menawarkan sumber daya barang atau jasa/pelayanan. Untuk itu dilakukan analisis ekonomi yang terkait dengan pelayanan kesehatan. Cara yang komperhensif untuk menentukan pengaruh ekonomi dari alternatif terapi obat atau intervasi kesehatan lain yaitu dengan analisis farmakoekonomi yang berupa costeffectiveness analysis (CEA) atau analisis efektivitas biaya. CEA merupakan metode evaluasi ekonomi yang dapat digunakan untuk pengambilan keputusan dalam memilih alternatif terbaik (Andayani, 2013).

\section{METODE PENELITIAN}

\section{Tempat dan Waktu Penelitian}

Penelitian ini dilaksanakan di RS. Bhayangkara Manado pada bulan Desember 2018 - February 2019.

\section{Jenis dan Rancangan Penelitian}

Jenis dan rancangan penelitian yang digunakan ialah penelitian deskriptif dengan pengambilan data secara retrospektif.

\section{Populasi dan Sampel Penelitian Populasi}

Populasi penelitian ini adalah semua pasien demam tifoid anak yang dirawat inap menggunakan antibiotik sefotaksim atau seftriakson.

\section{Sampel}

Sampel pada penelitian ini yaitu pasien rawat inap diagnosa terserang demam tifoid di RS Bhayangkara Manado sampel harus memenuhi kriteria, sebagai berikut :

A. Kriteria Inklusi

1) Pasien demam tifoid penggunaan terapi antibiotik Sefotaksim dan Seftriakson.

2) Pasien demam tifoid pada anak berumur $\leq 11$ tahun.

3) Pasien yang memiliki data lengkap.

B. Kriteria Eksklusi 
1) Pasien demam tifoid yang meninggal dunia.

2) Pasien demam tifoid dengan penyakit penyerta.

\section{Pengambilan Data}

Data yang digunakan dalam penelitian ini diambil dari catatan rekam medik pasien serta perincian biaya medik langsung dibagian administrasi dan keuangan di Rumah Sakit Bhayangkara Manado periode Januari Desember 2018.

\section{Analisis Data}

Data analisis secara deskriptif dan diuraikan dalam bentuk tabel. Setelah data terkumpulkan, dilakukan perhitungan biaya medik langsung (biaya pengobatan demam tifoid) pada tiap-tiap pasien. Kemudian dijumlah sesuai terapi pengobatan lalu dibuat rata-ratanya. Data ini dapat digunakan untuk menghitung rata-rata atau ACER seperti rumus berikut ini :

$$
A C E R=\frac{\text { BIAYA }}{\text { EFEK }}
$$

Keterangan :

Biaya $=$ Rata-rata biaya pengobatan .

Efek = outcome (efek) terapi obat.

Hasil dari CEA dapat disimpulkan dengan ICER (Incremental Cost-Effectiveness Ratio) seperti rumus berikut ini :

$$
I C E R=\frac{\Delta \text { Biaya }}{\Delta \text { Efek }}=\frac{\text { Biaya A-Biaya B }}{\text { Efek A-Efek B }}
$$

Keterangan :

Biaya $\mathrm{A}=$ Biaya Teknologi Baru

Biaya $\mathrm{B}=$ Biaya Pembanding

Efek $\mathrm{A}=$ Efek Teknologi Baru

Efek B = Efek Pembanding

\section{HASIL DAN PEMBAHASAN}

\section{Angka Kejadian Demam Tifoid}

Penelitian ini dilakukan di Bangsal

Anak Rumah Sakit Bhayangkara Manado. Seluruh pasien anak demam tifoid yang dirawat inap selama periode Januari Desember 2018 berjumlah 300 pasien, jumlah pasien di Bangsal Anak sebanyak 280 pasien dan berdasarkan sampel yang didapat 28 orang pasien anak demam tifoid yang memenuhi kriteria inklusi.

\section{Karakteristik Demam Tifoid berdasarkan} Jenis Kelamin

Tabel 1. Data Karakteristik Jenis Kelamin Pasien Anak Demam Tifoid di RS Bhayangkara Manado.

\begin{tabular}{ccc}
\hline $\begin{array}{c}\text { Jenis } \\
\text { Kelamin }\end{array}$ & N & Persentase\% \\
\hline $\mathrm{P}$ & 11 & $39 \%$ \\
\hline $\mathrm{L}$ & 17 & $61 \%$ \\
\hline Total & 28 & $100 \%$
\end{tabular}

Berdasarkan pada Tabel 1, diperoleh data bahwa pasien berjenis kelamin perempuan $39 \%$ lebih sedikit terserang demam tifoid dibandingkan pasien berjenis kelamin laki-laki 61\%. Rentannya anak lakilaki yang terserang demam tifoid karena aktivitas diluar rumah yang lebih banyak dilakukan anak laki-laki daripada anak perempuan seperti contohnya main diluar rumah dan jajan makanan atau minuman sembarangan yang tidak diketehui kebersihannya. Hasil ini diperkuat dengan penelitian yang menyatakan bahwa laki-laki memiliki risiko menderita demam tifoid dibandingkan dengan perempuan dikarenakan laki-laki lebih banyak melakukan aktivitas di luar rumah sehingga mengonsumsi makanan yang biasanya banyak mengandung penyedap rasa dan kebersihannya pun belum terjamin, dibandingkan dengan anak perempuan yang lebih menyukai masakan rumah daripada masakan dari luar rumah sehingga anak perempuan lebih memperhatikan kebersihan makanan yang akan dikonsumsi (Pramitasari, 
2013). Umumnya penyakit demam tifoid dapat juga menyerang siapa saja laki-laki maupun perempuan. Semua tergantung dari kebiasaan hidup anak yang kurang memperhatikan kebersihan, juga kondisi fisiologi dari masing-masing individu (Budiarto dkk, 2012).

\section{Karakteristik Demam Tifoid berdasarkan} Umur

Tabel 2. Data Karakteristik Umur Pasien Anak Demam Tifoid di RS Bhayangkara Manado.

\begin{tabular}{ccc}
\hline USIA & $\mathbf{N}$ & Presentase (\%) \\
\hline $\begin{array}{c}0-5 \\
\text { Tahun }\end{array}$ & 10 & $36 \%$ \\
\hline $\begin{array}{c}6-11 \\
\text { Tahun }\end{array}$ & 18 & $64 \%$ \\
\hline Total & 28 & $100 \%$ \\
\hline
\end{tabular}

Berdasarkan Pada Tabel 2, diperoleh data bahwa pasien anak berumur 0 - 5 tahun prevalensinya $36 \%$ sedangkan prevalensi terbanyak pada anak umur 6 - 11 tahun yaitu $64 \%$. Hal ini sesuai dengan penelitian yang dilakukan oleh Adisasmito (2006) bahwa angka kejadian tertinggi adalah pada anak usia 6 - 10 tahun. Pada anak usia 6-10 tahun merupakan masa anak mulai mengenal lingkungan dan mulai bersosialisasi dengan banyak orang, mereka mulai mengonsumsi makanan dan minuman yang tidak diketahui jelas kebersihan dari makanan dan minuman tersebut. Mereka juga lebih tidak memperhatikan kebersihan seperti sebelum makan lupa mencuci tangan atau makan jajanan kotor yang berada di pinggir jalan.

\section{Analisis Efektivtas Biaya}

Perhitungan Biaya Medik Langsung menggunakan Sefotaksim

Tabel 3. Direct medical cost penggunaan terapi antibiotik sefotaksim pada pasien demam tifoid di RS Bhayangkara.

\begin{tabular}{cccccc}
\hline NO & Nama & \multicolumn{3}{c}{ Komponen Biaya (Rp) } & Total (Rp) \\
\cline { 3 - 5 } & & $\begin{array}{c}\text { Biaya } \\
\text { Pengobatan }(\mathrm{Rp})\end{array}$ & $\begin{array}{c}\text { Biaya Perawatan } \\
(\mathrm{Rp})\end{array}$ & $\begin{array}{c}\text { Biaya Laboratorium } \\
(\mathrm{Rp})\end{array}$ & \\
\hline $\mathbf{1}$ & HK & 176.110 & 2.202 .000 & 80.000 & 2.415 .680 \\
\hline $\mathbf{2}$ & HN & 176.110 & 2.202 .000 & 80.000 & 2.415 .680 \\
\hline $\mathbf{3}$ & AS & 164.440 & 2.202 .000 & 80.000 & 2.415 .680 \\
\hline $\mathbf{4}$ & MB & 202.720 & 2.202 .000 & 80.000 & 2.415 .680 \\
\hline $\mathbf{5}$ & AM & 164.440 & 2.202 .000 & 80.000 & 2.415 .680 \\
\hline $\mathbf{6}$ & AR & 176.690 & 2.202 .000 & 80.000 & 2.415 .680 \\
\hline $\mathbf{7}$ & RP & 176.690 & 2.202 .000 & 80.000 & 2.424 .080 \\
\hline $\mathbf{8}$ & EA & 152.490 & 2.202 .000 & 80.000 & 2.424 .080 \\
\hline $\mathbf{9}$ & MS & 190.990 & 2.202 .000 & 80.000 & 2.430 .060 \\
\hline $\mathbf{1 0}$ & HD & 158.690 & 2.202 .000 & 80.000 & 2.430 .060 \\
\hline $\mathbf{1 1}$ & PR & 152.970 & 2.658 .000 & 80.000 & 2.907 .890 \\
\hline $\mathbf{1 2}$ & HT & 152.970 & 2.658 .000 & 80.000 & 2.907 .890 \\
\hline \multicolumn{7}{c}{ Total Direct Medical Cost } \\
\hline \multicolumn{7}{c}{ Direct medical cost per pasien } \\
\hline
\end{tabular}

Perhitungan biaya medik langsung terdapat tiga komponen yaitu biaya pengobatan, biaya perawatan dan biaya laboratorium. Biaya pengobatan yaitu biaya obat dan biaya alat medis yang digunakan selama pasien dirawat inap, sedangkan biaya perawatan terdiri dari biaya akomodasi Rp. 150.000/hari, biaya visit dokter umum Rp $35.000,-$, biaya visit dokter spesialis Rp. 55.000,- biaya tindakan medik seusai dengan perawatan selama di rawat inap dan biaya administrasi Rp. 35.000,-. Biaya laboratorium 
yang terdiri dari biaya pemeriksaan widal yang dikenakan biaya Rp. 80.000,-.

Berdasarkan Tabel 3, total biaya medik langsung dengan total biaya terbesar yaitu Rp 2.907.890,- dan total biaya medik langsung terkecil Rp.2.415.680,-. Total direct medical cost yang dikeluarkan 12 pasien anak yaitu sebesar Rp.30.018.140,- dengan direct medical cost per pasien anak yaitu sebesar Rp.2.501.511,--.

\section{Perhitungan Biaya Medik Langsung menggunakan Seftriakson}

Tabel 4. Direct medical cost penggunaan seftriakson pada pasien demam tifoid di RS Bhayangkara Manado

\begin{tabular}{cccccc}
\hline \multirow{2}{*}{ No } & Nama & \multicolumn{3}{c}{ Komponen Biaya (Rp) } & Total (Rp) \\
\cline { 3 - 5 } & & $\begin{array}{c}\text { Biaya } \\
\text { Pengobatan }(\mathrm{Rp})\end{array}$ & $\begin{array}{c}\text { Biaya } \\
\text { Perawatan } \\
(\mathrm{Rp})\end{array}$ & $\begin{array}{c}\text { Biaya } \\
\text { Laboratorium }(\mathrm{Rp})\end{array}$ & \\
\hline $\mathbf{1}$ & LP & 196.360 & 1.746 .000 & 80.000 & 2.022 .360 \\
\hline $\mathbf{2}$ & DP & 196.360 & 1.746 .000 & 80.000 & 2.022 .360 \\
\hline $\mathbf{3}$ & RM & 196.360 & 1.746 .000 & 80.000 & 2.022 .360 \\
\hline $\mathbf{4}$ & NS & 196.360 & 1.746 .000 & 80.000 & 2.022 .360 \\
\hline $\mathbf{5}$ & SR & 196.360 & 1.746 .000 & 80.000 & 2.022 .360 \\
\hline $\mathbf{6}$ & FP & 207.360 & 1.746 .000 & 80.000 & 2.033 .360 \\
\hline $\mathbf{7}$ & PS & 207.360 & 1.746 .000 & 80.000 & 2.033 .360 \\
\hline $\mathbf{8}$ & CC & 172.180 & 1.746 .000 & 80.000 & 1.998 .180 \\
\hline $\mathbf{9}$ & SK & 172.180 & 1.746 .000 & 80.000 & 1.998 .180 \\
\hline $\mathbf{1 0}$ & MW & 163.780 & 1.746 .000 & 80.000 & 1.989 .780 \\
\hline $\mathbf{1 1}$ & KB & 156.240 & 1.746 .000 & 80.000 & 1.982 .240 \\
\hline $\mathbf{1 2}$ & AK & 170.540 & 1.746 .000 & 80.000 & 1.996 .540 \\
\hline $\mathbf{1 3}$ & AR & 209.680 & 1.746 .000 & 80.000 & 2.035 .680 \\
\hline $\mathbf{1 4}$ & CK & 172.560 & 2.202 .000 & 80.000 & 2.454 .560 \\
\hline $\mathbf{1 5}$ & GA & 252.640 & 2.202 .000 & 80.000 & 2.534 .640 \\
\hline $\mathbf{1 6}$ & MB & 252.640 & 2.202 .000 & 80.000 & 2.534 .640 \\
\hline & & Total Direct Medical Cost & & 2.106 .435 \\
\hline & & Direct medical cost per pasien & & \\
\hline & Ber & & \\
\hline
\end{tabular}

Berdasarkan Tabel 4, total biaya medik langsung dengan total biaya terbesar yaitu sebesar Rp 2.534.640,- dan total biaya medik langsung terkecil sebesar Rp.1.982.240,-. Total direct medical cost yang dikeluarkan pasien untuk mendapatkan pelayanan kesehatan dengan menggunakan antibiotik seftriakson untuk ke 16 pasien anak yaitu sebesar Rp.33.702.960,- dengan direct medical cost per pasien anak yaitu sebesar Rp.2.106.435,--

Perbedaan biaya medik masingmasing pasien dikarenakan lamanya pasien dirawat inap di rumah sakit, semakin cepat pasien dirawat dirumah sakit maka semakin kecil biaya yang harus dikeluarkan pasien. 


\section{Perhitungan Efektivitas Biaya Berdasarkan ACER}

Tabel 5. Perhitungan ACER penggunaan Seftriakson dan Sefotaksim pada pasien anak demam tifoid di RS Bhayangkara Manado.

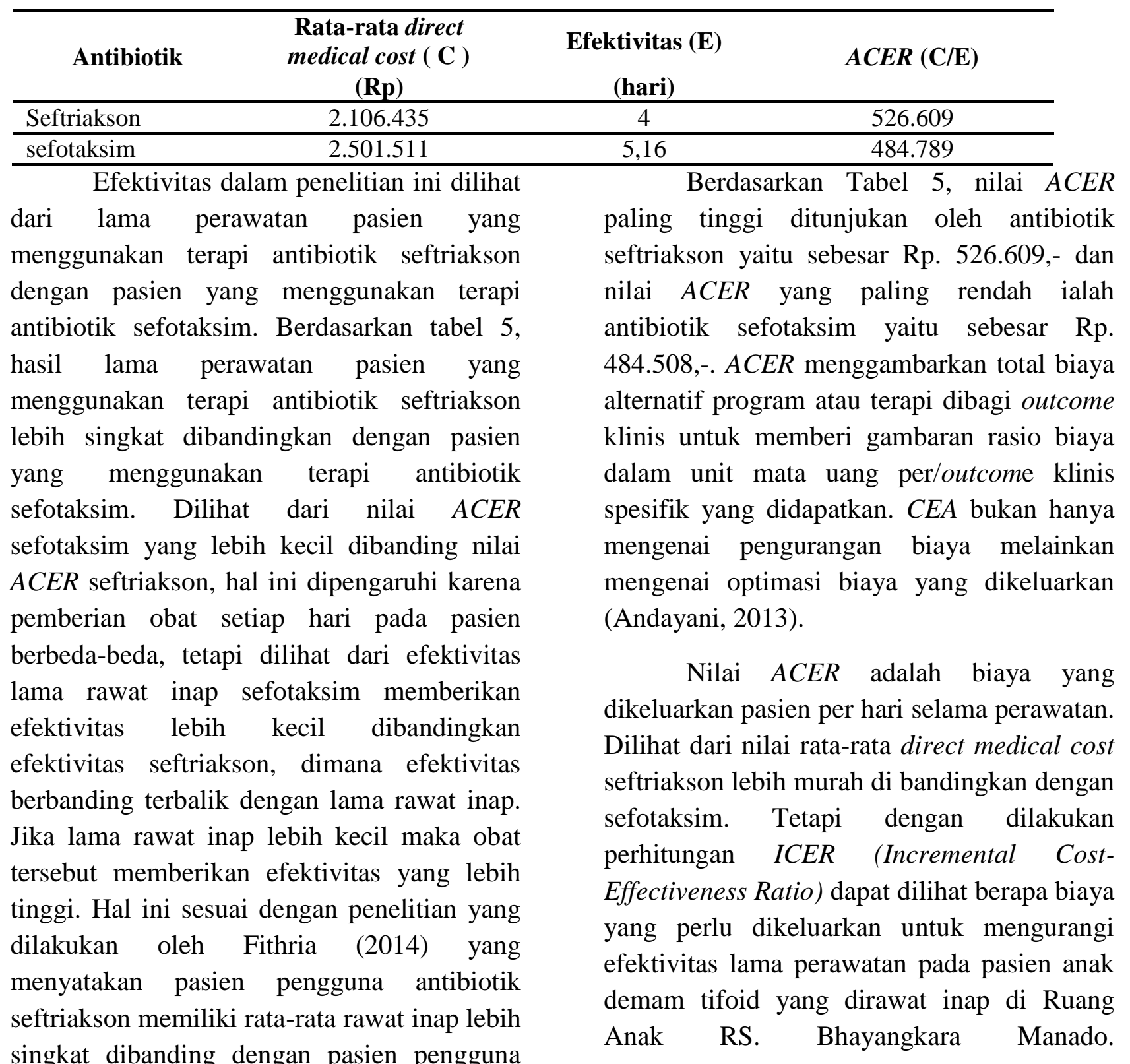
antibiotik sefotaksim. 
Tabel 6. Hasil Perhitungan ICER antibiotik Sefotaksim dan Seftriakson untuk pasien anak Demam Tifoid di RS Bhayangkara.

\begin{tabular}{ccc}
\hline $\boldsymbol{\Delta C}$ & $\boldsymbol{\Delta E}$ & ICER $(\boldsymbol{\Delta C} / \mathbf{\Delta E})$ \\
\hline $2.106 .435-2.501 .511=$ & $4-5,16=$ & 340.582 \\
\hline-395.076 & $-1,16$ & \\
\hline
\end{tabular}

Berdasarkan Tabel 6, diperoleh nilai ICER yaitu Rp. 340.528,-. Dari nilai ICER tersebut menunjukan bahwa ketika pasien pengguna terapi sefotaksim menginginkan untuk mendapatkan peningkatan efektivitas yang setara dengan pasien pengguna terapi seftriakson, maka perlu menambahkan total biaya sebesar Rp.340.528,- per satu peningkatan satu unit efektivitas. Nilai ICER yang dihasilkan dari perbandingan ini sesuai dengan rumus perhitungan ICER (Kemenkes, 2013). Jika rumah sakit menginginkan peningkatan efektivitas penyembuhan demam tifoid per pasien dengan menggunakan seftriakson, maka perlu penambahan biaya sesuai dengan hasil perhitungan ICER. Namun dalam penelitian ini penambahan biaya ketika akan berpindah pengobatan ke seftriakson didapat dengan hasil yang lebih murah dibandingkan pasien yang tetap menggunakan sefotaksim.

Hanya saja biaya yang di keluarkan pasien yang berpindah dari sefotaksim ke seftriakson berbeda dengan pasien yang dari awal pengobatan telah menerima pengobatan terapi seftriakson. Dalam pengambilan keputusan pemilihan penggunaan antibiotik pada pasien anak demam tifoid tergantung dari dokter yang menangani pasien anak demam tifoid di rumah sakit tersebut (Nurmainah, 2017).

\section{Kesimpulan}

Dari hasil penelitian yang dilakukan disimpulkan bahwa penggunaan terapi antibiotik yang memiliki efektivitas tinggi yaitu terapi antibiotik seftriakson dibandingkan dengan terapi antibiotik sefotaksim, dilihat dari lama rawat inap seftriakson lebih singkat dibanding lama rawat inap sefotaksim. Maka jika pasien anak demam tifoid akan berpindah pengobatan dari pengobatan sefotaksim ke pengobatan seftriakson perlu menambahkan biaya sebesar nilai ICER yaitu Rp. 340.528,-. Sehingga pengobatan terapi antibiotik seftriakson lebih efektif dari segi manfaat dan biaya.

\section{Saran}

Agar penelitian dilakukan secara prospektif sehingga dalam pengambilan data pasien dapat lebih akurat dan data biaya medis tidak langsung dapat diketahui.

\section{DAFTAR PUSTAKA}

Adisasmito, A.W., 2006, Penggunaan Antibiotik Pada Terapi Demam Tifoid Anak di RSAB Harapan Kita. Sari Pediatri; 8: 174-80

Andayani, T.M. 2013. Farmakoekonomi : Prinsip dan Metodologi. Bursa Ilmu, Yogyakarta.

Budiarto \& Anggraeni. 2012. Pengantar 
Epidemiology. EGC : Jakarta.

Departemen kesehatan Republik Indonesia.

Keputusan Menteri Kesehatan Republik Indonesia No. 364 : Pedoman pengendalian demam tifoid. Jakarta: Departemen Kesehatan Republik Indonesia; 2006.

Etikasari, R., Andayani, T.M., and Mukti, A.G., 2012, Analisis Biaya dan Kesesuaian Penggunaan Antibiotik pada Demam Tifoid di RSUD Kota Yogyakarta. J. Manaj. dan Pelayanan Farmasi. JMPF J. Manag. Pharm. Pract. 2. 147-153.

Fitriah R.F., Damayanti K., Fauziah R.P., 2014, Perbedaan Efektivitas Antibiotik Pada Terapi Demam Tifoid Di Puskesmas Bancak Kabupaten Semarang Tahun 2014. ISBN: 978-60219556-2-8.

Hadinegoro, S.R.S., 2011, Demam Tifoid pada Anak: Apa yang perlu diketahui?, Itokindo

Istiantoro, Y.H., Vincent H.S. 2011. Penisilin, Sefalosporin, dan Antibiotik Bektalaktam Lainnya : Farmakologi dan Terapi Edisi 5. Fakultas Kedokteran UI, Jakarta

Juwono, R., Prayitno, A. 2005. Terapi Antibiotik. Dalam : Farmasi Klinik, Ed Aslam PT. Elex Media Komputindo Kelompok Gramedia. Jakarta.

Kemenkes RI, (2013). Pedoman Penerapan Kajian Faermakoekonomi , Jakarta: Kementrian Kesehatan Republik Indonesia.

Kemenkes RI. Profil Kesehatan Indonesia
Tahun 2014. Jakarta : Kemenkes RI; 2015

Lacy, C.,F.Amstrong,. et al., 2010., Drug Information Handbook $18^{\text {th }}$ Edition, Lexi Comp, New York

Nurmainah, Siti S., 2017, Efektivitas Biaya Penggunaan Ampisilin Dan Sefotaksim Pada Pasien Anak Demam Tifoid JMKMI . Vol $13 ; 2$

Pramitasari. 2013. Faktor Resiko Penyakit Demam Tifoid Pada Penderita Yang Dirawat Di Rumah Sakit Umum Daerah Ungaran. Tesis Diponogoro: Diponogoro University.

Stoesser, N., Eyre. D, Basnyat,B. Parry, C., 2013, Treatment of enteric fever (tifoid dan paratifoid fever) with third and fourth generation cephalosporins (protocol), Cochrane Database of Systemic Reviews,3,1-12.

World Health Organization (WHO), 2014, Focus of Tifoid Fever, Weekly EWARN weely summary, 1-2. 